\section{Mössbauer spectroscopy and its chemical applications.} Edited by John G. Stevens and Gopal K. Shenoy. Advances in chemistry series No. 194. Pp. xiii +642 . American Chemical Society, Washington, DC, 1981. Price DM 62.00, US \$28.20.

This substantial volume is based on a symposium of the American Chemical Society at Houston in March 1980 in that twenty-nine papers were selected for publication (seven of them in an extended form) to illustrate Mössbauer spectroscopy and its chemical applications. Although some of the results described are available elsewhere in the literature, the style of presentation in this volume is more discursive than usual, and a number of the contributions contain extensive and valuable review material. The large number of authors prevents individual mention, but many of the names will be very familiar to the cognoscenti. The papers have been grouped under eight main headings, although the resulting arrangement seems rather curious, and the distinction between extended and shorter papers is less marked than may have been the original intention.

The section on Chemical bonding features two papers on molecular-orbital calculations as applied to chlorine, bromine and iodine compounds, and to chemical bonding in gold compounds and alloys. The layman may find these difficult to digest at first reading.

Conversion electron Mössbauer spectroscopy is reviewed by Tricker, who gives a useful account of the principles of the technique as applied to ${ }^{57} \mathrm{Fe}$ and ${ }_{119} \mathrm{Sn}$ and its application to materials and surface science. The three supporting papers give details of preliminary experiments using ${ }^{151} \mathrm{Eu}$ and ${ }^{169} \mathrm{Tm}$; depthselective measurements for ${ }^{3} \mathrm{Fe}$ using an electron spectrometer; and some typical results for ${ }^{57} \mathrm{Fe}$ implanted in copper foils and for glazes on ancient artefacts.

Four of the five papers on Environmental applications are concerned with various aspects of the characterization of coal by means of the iron mineral content; the exception discusses the analysis of iron oxides in soil.

The review under the heading of Analytical applications concentrates specifically on the steel industry and the characterization of ores, coal and steel products.

A short paper by Munck on Biological applications gives the recent evidence for a new three-iron centre in ferre- doxins, and is an excellent illustration of the complementary use of EPR and Mössbauer spectroscopy in this field.

Five papers on the less commonly used isotopes cover ${ }^{67} \mathrm{Zn}$ in the zinc chalcogenides, ${ }^{237} \mathrm{~Np}$ in organoneptunium compounds, ${ }^{121} \mathrm{Sb}$ in the reaction products of $\mathrm{SbCl}_{5}$ with ketimines, ${ }^{127} \mathrm{I}$ in cations and anions of iodine, and ${ }^{125} \mathrm{Te}$, ${ }^{129} \mathrm{P}$ in tellurium metal under high pressures.

The four papers on Phase analysis are introduced by an excellent paper by Gütlich on spin-crossover phenomena which has been one of the most fruitful areas of application of the technique; the shorter contributions discuss spincrossover effects under high pressure. relaxation effects associated with magnetic transitions, and ferroelectric transitions studied with the ${ }^{181} \mathrm{Ta}$ resonance.

The final seven papers disc:ıss various Energy and catalyst applications including such diverse topics as hydrogen storage materials, battery materials, and various catalyst systems. A comprehensive index is also includer.

This volume illustrates the trend in recent years for Mössbauer spectroscopy to be used more extensively in materials research, and the range of topics covered shows how successful this change in emphasis has been. Many of the authors have shown commendable candour in discussing the limitations of and the problems associated with their work. Although this is not a comprehensive account of the chemical applications of Mössbauer spectroscopy, the book nevertheless does give a good flavour of what is being achieved, and is a praiseworthy addition to the Advances in Chemistry Series.

TERENCE C. GIBB

\section{Department of Inorganic and Structural Chemistry University of Leeds \\ Leeds LS2 9JT \\ England}

\section{J. Appl. Cryst. (1982). 15, 579}

\section{Chemical vapor deposition 1960-1980, a bibliography. Edited by D. T. Hawkins. Pp. xi +736. New York: IFI Data Base Library (a division of Plenum), 1981. Price US $\$ 115.00$.}

This 736 page book is intended as a reference book for those working in the field of chemical vapour deposition (CVD). The number of articles on CVD showed an enormous increase around 1966 to more than 500 papers per year between 1970 and 1980. CVD started with the purification of materials, later protective coatings were made. The main emphasis, however, comes from the electronics industry, where CVD plays an increasingly useful role in the deposition of high-purity materials, metals, semiconductor materials and reiractories in the form of monocrystalline (epitaxial), polycrystalline or amorphous deposits. Receintly, solid-state lasers have been made by CVD techniques to produce the light transmitted through optical fibres also made by CVD.

The bibliography contains over 5000 entries, complete with the title of the paper, and is organized in 17 sections: Theory, Models, Calculations; Apparatus, Methods, Techniques; Thermodynamics, and a number of sections on specific materials. Very conveniently also, abstract numbers from Chemical Abstracts and Science Abstracts $A$ and $B$ are listed. No section on structure is available but such information can be found in the permuted title (key word in context) index in which three pages show the word 'structure' to appear in the titles of about 230 papers. This type of index has proven to be of great help in searching the literature for a specific problem, a number of checks confirmed this point. More than half of the content of the book is devoted to this index. An alphabetic index on all the authors with the title of the papers concludes the reference book.

In conclusion, the book will be very useful as a handy reference to existing literature, especially at the start of a new line of work. By nature the number of readers will be restricted to the rather large CVD community in which the study of thermodynamics, equilibrium and kinetics, structure and defects go hand in hand with, for example, gas flow dynamics, surface studies, and optical tools to identify reaction intermediates.

Research Laboratories

J. BLOEM

NV Philips' Gloeilampenfabrieken

PO Box 80,000

5600 JA Eindhoven

The Netherlands

\section{J. Appl. Cryst. (1982). 15, 579-580}

\section{Neutron transmutation doped sili-} con. Edited by Jens Guldberg. Pp xi +505 . New York: Plenum Press, 1981. Price US $\$ 59.50$.

This volume contains the papers presented at the Third International Conference on Neutron Transmutation Doping (NTD) held in Copenhagen on 27-29 August 1980. The two first symposia on NTD were arranged in Oak Ridge (1976) and in the University of Missouri (1978), and the next one will be held in Gaithersberg (June 1982). 